\title{
Earthquake and tsunami recovery efforts in northeastern Japan
}

\author{
M. Takezawa ${ }^{1}$, S. Kamao ${ }^{1}$, A. Satoh ${ }^{2}$, T. Satoh ${ }^{2}$, Y. Suzuki ${ }^{2}$ \\ \& J. Shibata ${ }^{2}$ \\ ${ }^{I}$ Nihon University, Japan \\ ${ }^{2}$ Shiogama City, Japan
}

\begin{abstract}
The earthquake and tsunami that struck on March 11, 2011, caused extensive structural damage over widespread areas of northeastern Japan, inflicted heavy damage to roads and railways, caused numerous fires, and was responsible for a dam collapse. In response to the disaster, the Japanese National Diet passed the Law to Establish the Reconstruction Agency on December 9, 2011, and the Agency was subsequently inaugurated on February 10, 2012, under the direct leadership of the prime minister $[1,2]$. In this paper, on and reconstruction activities implemented in areas struck by the earthquake and tsunami are described, focusing on Shiogama City, which is located in Miyagi Prefecture about $15 \mathrm{~km}$ north of Sendai. Although damage to Shiogama City's fishing industry turned out to be slight, nearly 50 people were killed or went missing in the city, and approximately 4,000 houses were completely or partially destroyed by the tsunami. Up to now, recovery and reconstruction plans were rapidly formulated by Japanese central government and Shiogama City officials.

Keywords: earthquake, tsunami, recovery, reconstruction.
\end{abstract}

\section{Introduction}

The Great East Japan Earthquake, which occurred off the Pacific coast of northeastern Japan on March 11, 2011, was measured by the US Geological Survey (USGS) moment magnitude scale $\left(\mathrm{M}_{\mathrm{w}}\right)$ as a magnitude 9.03 undersea mega-thrust event, with the epicenter approximately $70 \mathrm{~km}$ east of the Oshika Peninsula which projects southeast into the Pacific Ocean from the coast of Miyagi Prefecture in northeast of the main island of Japan and a hypocenter at an 
underwater depth of approximately $32 \mathrm{~km}$. It was the most powerful known earthquake ever to have hit Japan, and one of the five most powerful earthquakes occurring worldwide since modern record keeping began in 1900. The earthquake triggered powerful tsunami waves that reached heights of up to $40.5 \mathrm{~m}$ in Miyako, Iwate Prefecture, while waves travelled up to $10 \mathrm{~km}$ inland in the Sendai area. The earthquake moved the main island of Japan $2.4 \mathrm{~m}$ east and shifted the Earth on its axis by estimates of between 10 and $25 \mathrm{~cm}$. On September 12, 2012, the Japanese National Police Agency confirmed about 15,900 deaths, 6,100 persons injured, and 2,700 persons missing across twenty prefectures. They also reported that about 130,000 buildings had totally collapsed, 254,200 buildings were "half collapsed," and another 700,000 buildings were partially damaged. In response, the Bank of Japan offered ¥15 trillion (US \$183 billion) to the banking system on March 14, 2011 in an effort to normalize market conditions. The World Bank has estimated that the economic cost of the disaster at approximately US \$235 billion, making it the costliest natural disaster in world history [1].

\section{The great East Japan earthquake}

Major earthquakes with accompanying large tsunamis previously struck the Sanriku Coast region in 1896 and in 1933. The Great East Japan Earthquake, which was caused by a 5-8 m up-thrust on a $180 \mathrm{~km}$ wide stretch of seabed 60 $\mathrm{km}$ off the Sanriku Coast, resulted in a major tsunami that inflicted destruction along the Pacific coastline of all Japan's northern islands. Thousands of lives were lost as entire towns were devastated. The tsunami propagated throughout the Pacific Ocean region reaching the entire Pacific coast of North and South America from Alaska to Chile. Warnings were issued and evacuations were carried out in many countries bordering the Pacific, even though the affects were minor. For example, Chile's Pacific coast, which is about 17,000 km away from Japan, was struck by waves $2 \mathrm{~m}$ high, compared with an estimated wave height of $38.9 \mathrm{~m}$ experienced on the east peninsula of Miyako City in Iwate prefecture. Immediately after the earthquake, the Japan Meteorological Agency (JMA) issued a "major tsunami" warning. This is the most serious warning on its scale, and is defined as a prediction of waves at least three meters high. When it struck, the tsunami inundated a total area of approximately $561 \mathrm{~km}^{2}$ of Japan. However, a government study conducted in the aftermath of the disaster found that only $58 \%$ of people in coastal areas of Iwate, Miyagi, and Fukushima Prefectures heeded the tsunami warnings immediately after the earthquake and began evacuating to higher ground. Of those who decided to evacuate after hearing the warning, only $5 \%$ were caught by the tsunami. Of those persons in the affected area who ignored the warning, the tsunami waters hit 49\%. Figure 1 shows the Japanese archipelago [3].

Although Japan has invested the equivalence of billions of dollars on antitsunami seawalls, which line at least $40 \%$ of its $34,751 \mathrm{~km}$ coastline and stand up to $12 \mathrm{~m}$ high, the tsunami simply washed over the top of many of them, collapsing a number of them in the process. Damaged buildings included 29,500 


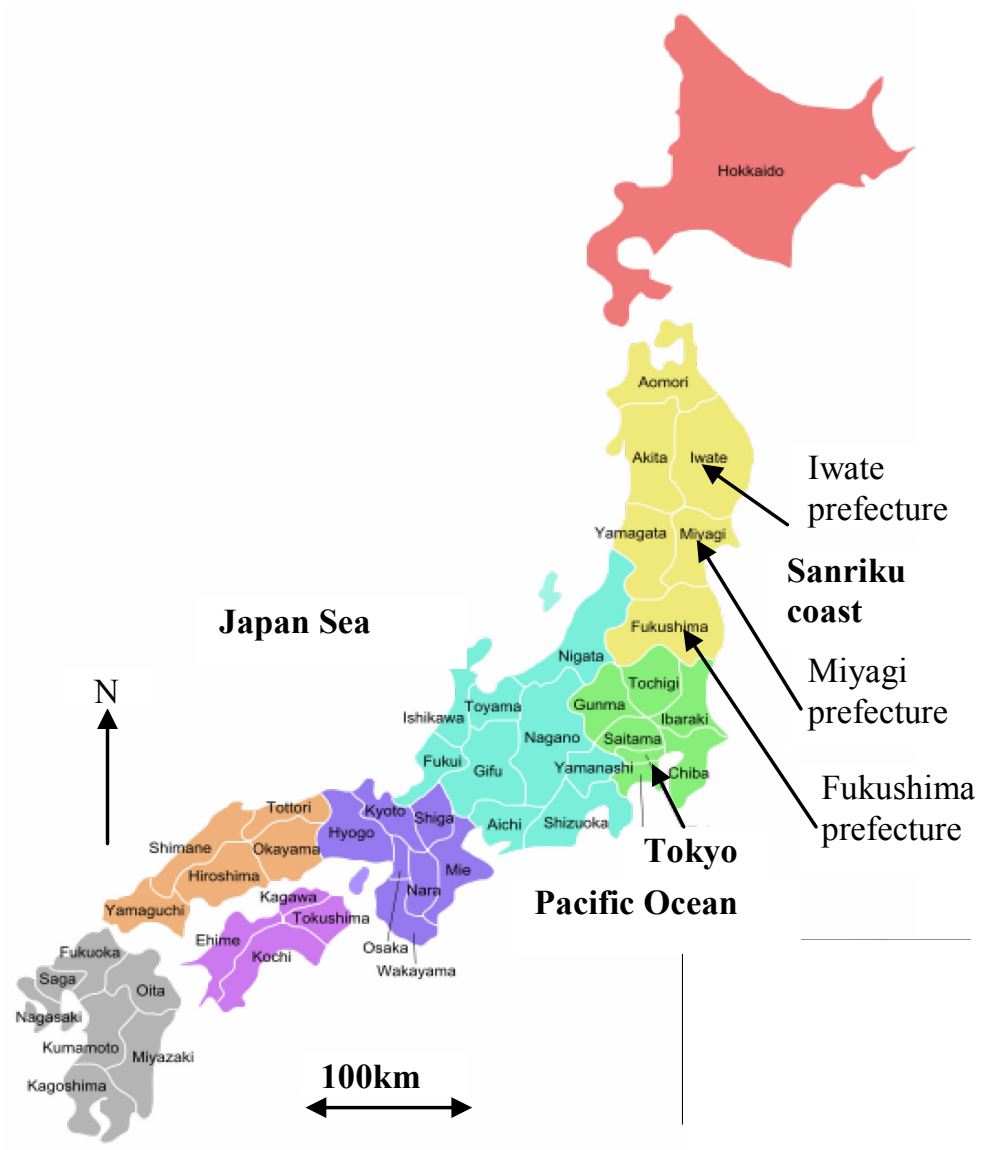

Figure 1: Japanese archipelago.

structures in Miyagi Prefecture, 12,500 in Iwate Prefecture and 2,400 in Fukushima Prefecture. Three hundred hospitals with 20 beds or more were damaged by the disaster, with 11 being completely destroyed. In addition, the earthquake and tsunami created an estimated 24-25 million tons of rubble and debris, and an estimated 230,000 automobiles and trucks were damaged or destroyed in the disaster. As of the end of May 2011, residents of Iwate, Miyagi, and Fukushima Prefectures had requested deregistration of 15,000 vehicles, indicating that the vehicle owners had written them off as irreparable or unsalvageable. All of Japan's ports were briefly closed after the earthquake, even though those in Tokyo Bay and further south soon reopened. Fifteen ports of Sendai, Shiogama, Souma, Kamaishi, etc. were located in the disaster zone. A total of 319 fishing ports, comprising approximately $10 \%$ of Japan's total, were damaged in the disaster. However, most had been restored to operation by April 18, 2012. The tsunami also ruptured the Fujinuma irrigation dam in Sukagawa 
City, Fukushima Prefecture, causing flooding that washed away five homes. After the disaster, 252 dams were inspected and it was discovered that six embankment dams had shallow cracks on their crests. The reservoir of one concrete gravity dam was found to have suffered a small minor slope failure. Currently, however, all those damaged dams are functioning without problems. In the immediate aftermath of the disaster, at least 1.5 million households were reported to have lost access to potable water. According to the Ministry of Economy, Trade and Industry (METI), around 4.4 million households served by

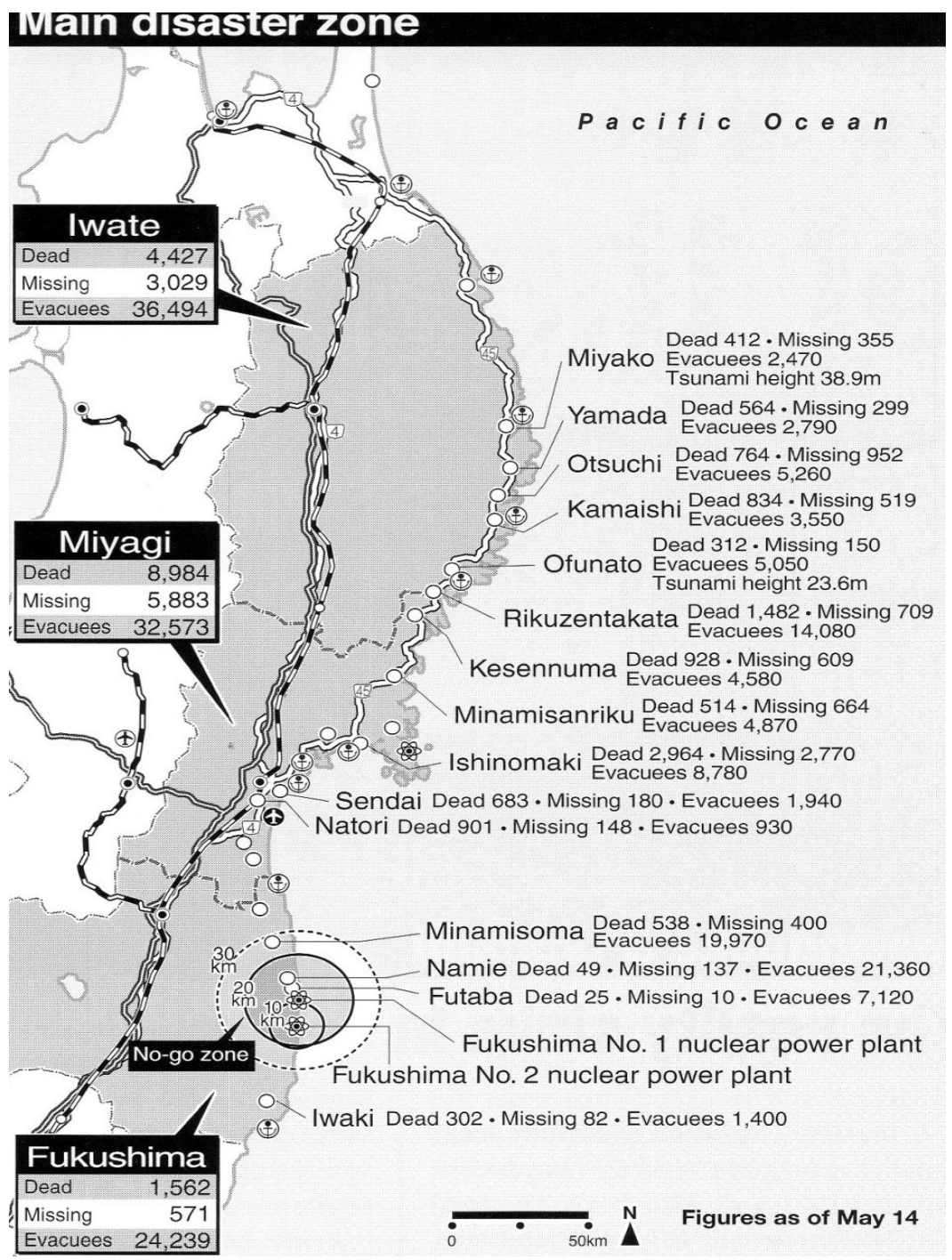

Figure 2: $\quad$ Main disaster zone of Sanriku Coast. 
Tohoku Electric Power (TEP) in northeastern Japan were left without electricity. Further south, several nuclear and conventional power plants went offline after the earthquake, reducing the total generating capacity of Tokyo Electric Power Company (TEPCO) by $21 \mathrm{GW}$, and caused "rolling blackouts," which began on March 14 due to the resulting power shortages. The reactors at the Fukushima No.1 and No. 2 Nuclear Power Plants were automatically taken offline when the first earthquake occurred, yet sustained major damage due to the subsequent tsunami. The $30 \mathrm{~km}$ radius around the nuclear power plants could not be assessed in the immediate aftermath of the earthquake and tsunami. Many sections of the Tohoku Expressway serving northern Japan were damaged as well. As for rail services, the Tohoku Shinkansen line was worst hit, with JR East Railway Co. estimating that 1,100 sections of the line, varying from collapsed station roofs to bent power pylons, required repair. In Tokyo, all railway services were suspended, leaving an estimated 20,000 people stranded at major stations across the city. In the hours after the earthquake, some train services resumed, but most lines serving the Tokyo area did not return to full service until the next day. Various train services around other parts of Japan were also canceled, with JR East suspending all its services nationwide for the remainder of the day. One hour after the earthquake, the resulting tsunami swept over Sendai Airport located on in the eastern part of the city, causing severe damage there [1]. Figure 2 shows the main disaster zone in the Sanriku Coast on May 14, 2011 [4].

\section{Shiogama City case study}

As previously mentioned, Shiogama City is located in Miyagi Prefecture and is situated on the northeastern Sanriku Coast between the cosmopolitan city of Sendai and Matsushima Bay, which is known as one of the three most famed views in Japan. The city has prospered due to its harbor, which has been a prominent center of maritime trade since the Meiji Era (1868-1912), even though it has more recently evolved into a base for the local and deep-sea fishing industries. Indeed, Shiogama City's harbor boasts the largest unloading point for fresh tuna in Japan, and its other enterprises ensure the city with an abundance of other fresh seafood. In addition to being a popular tourist destination due to its position as one of the doorways to Matsuhima Bay, Shiogama has more sushi restaurants per square kilometer than anywhere else in Japan and leads the nation in the production of steamed fish paste, kneaded fish cakes, as well as other processed fish products. In 2012, the city's population was 56,490, and the number of households was 20,363. Shiogama City covers an area of $17.79 \mathrm{~km}^{2}$. Figures 2(a) and (b) show overviews of Miyagi Prefecture and Shiogama City $[5,6]$.

In $2010,11.4 \%$ of the Shiogama City population was under 15 years of age $(6,437), 61.1 \%$ were citizens $15-64$ years of age $(34,451)$, while those citizens aged 65 and older $(15,481)$ accounted to $27.5 \%$ of the total. Of the 20,363 total households in the city, 59.6\% were nuclear family households $(12,115)$, independent households accounted for approximately $22.1 \%(4,500)$, elderly 

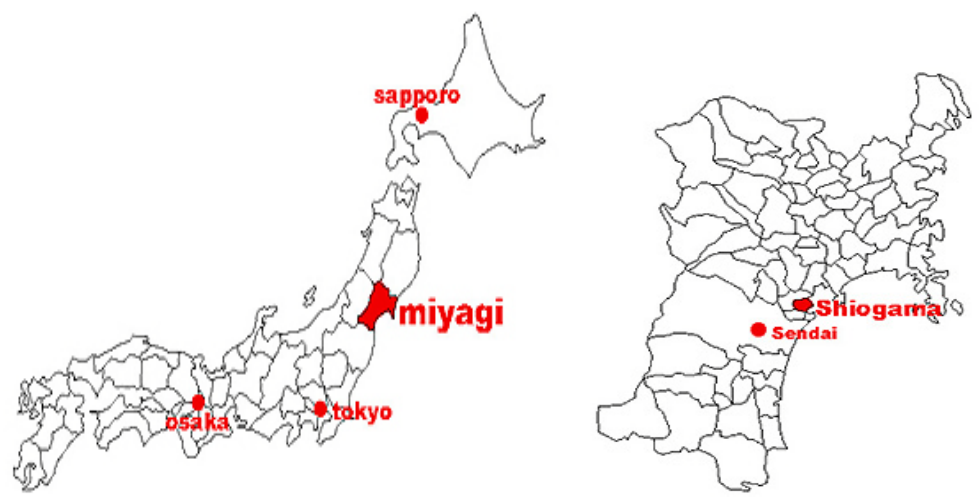

Figure 3: (a): Miyagi Prefecture. (b): Shiogama City.

couple households accounted for $12.5 \%(2,525)$ and households consisting of aged persons living alone accounted for $9.8 \%(1,998)$ of the total. As for the housing conditions in Shiogama, of the 19,880 total residential units surveyed in 2008, 14,180 were family-owned residences and 5,570 were rental units. In 2009, the city hosted 3,285 offices and employed 23,259 persons broken down as follows: primary industry, eight offices and 131 persons; secondary industries, 552 offices and 5,501 persons; tertiary industries, 2,725 offices and 17,627 persons. Damages resulting from the Great East Japan Earthquake in Shiogama City were as follows: 47 persons deceased due to immediate affects $(0.08 \%)$, and another 10 persons deceased due to causes related to the disaster $(0.02 \%)$. Damages resulting from of the tsunami inundation affected 18,718 persons (33.1\%), 6,973 households (34.2\%), 2,481 offices (75.5\%) and 18,596

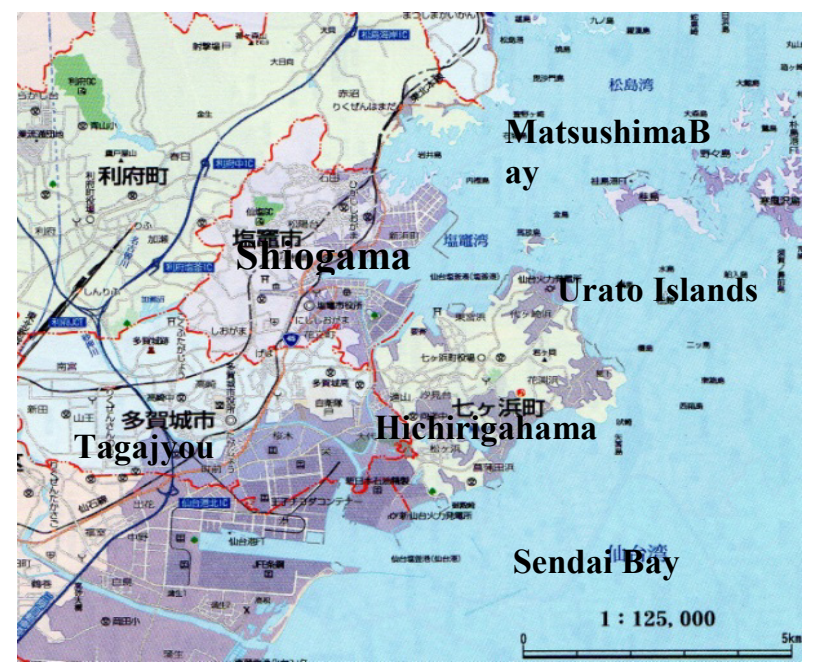

Figure 4: $\quad$ Flooded areas (shadowed) in Shiogama City. 


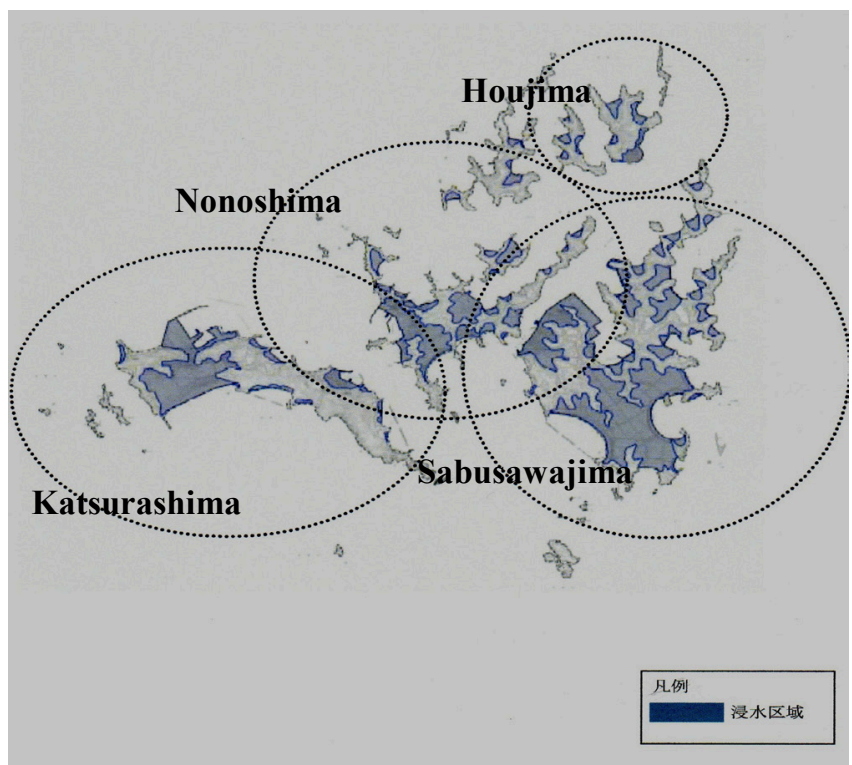

Figure 5: $\quad$ Urato islands of Shiogama City.

employees $(80 \%)$. The tsunami inundated approximately 27 ha of agricultural land (37\%) resulting in extensive damage to cultivated fields. Monetary damages in Shiogama City related to traffic facilities, communication lifelines, housing, education, medicine, etc., were estimated at approximately $¥ 0.1$ billion (US $\$ 0.1$ million) [7-9]. However, the city suffered slightly less damage than neighboring municipalities (Tagajyou City, Hichirigahama Town, etc.) because nearby offshore islands such as Katsurashima, Nonoshima, Sabusawajima and Houjima of Urato islands absorbed and dissipated much of the tsunami's force. Figure 4 shows an overview of the tsunami flooding in Shiogama City. Figure 5 is offshore islands and shadowed parts are flooding areas.

\section{Earthquake disaster reconstruction plans}

The Reconstruction Agency is an administrative body of the Cabinet of Japan established on February 2, 2012, to coordinate reconstruction activities related to the Great East Japan Earthquake and the Fukushima Daiichi Nuclear Power Plant disaster [10]. The Reconstruction Agency was established to replace the Reconstruction Headquarters that was created on June 24, 2011, in response to the Great East Japan Earthquake. At its founding, the Reconstruction Agency was headed by then Prime Minister who took direct control of the agency in an effort to strengthen the organization's leadership. Although the Reconstruction Agency is not a Cabinet Office, its authority extends over many other government ministries. The Reconstruction Agency is scheduled to exist for ten years, which was estimated to be the length of time necessary to fully restore the 
region after the disaster, and is expected to be dissolved on March 3, 2021. Currently, the Agency works out of three regional offices that were established in Iwate, Miyagi, and Fukushima Prefectures, along with two smaller offices, one in Hachinohe, Aomori Prefecture and the other in Mito, Ibaraki Prefecture. The Agency has since forged ties with major Japanese business associations as part of efforts to establish or revive economic activity in regions affected by the earthquake, tsunami, and the nuclear disaster. One such effort is the Reconstruction Design Council, which joins the Reconstruction Agency with the Japan Business Federation, the Japan Association of Corporate Executives, the Japan Chamber of Commerce and Industry, and their affiliated corporations [9]. Furthermore, the Agency also proposed an earthquake disaster reconstruction plan for Shiogama City, which aimed at reestablishing and ensuring safety there. The basic plan calls for

(1) regenerating the local infrastructure and constructing a community spirit that fosters cooperation among diverse support groups,

(2) promoting a citizen-based community where people can resist disasters so that all residents can live in safety,

(3) regenerating and reconstructing basic industries, commerce and infrastructure, including tourism-related enterprises,

(4) other actions as necessary to stimulate the regional economy.

The basic policies of the plan center on the following:

(1) Housing and lifestyle reconstruction, including rehabilitation and reconstruction of damaged/destroyed residences, promoting and maintaining employment, providing economic support to victims, as well as reviving and rebuilding public services.

(2) Improving community safety by enhancing the security and maintainability of the residential environments, reconstructing public facilities, reconstructing and stabilizing city functions and infrastructure, with specific emphasis on areas affected by the tsunami.

(3) Revitalizing commerce and other areas of the economy by rebuilding and reconstructing key industries, rebuilding and revitalizing commercial infrastructure, promoting tourism, and creating a new support system at the national and prefectural level.

(4) Addressing issues related to radioactive fallout. This includes promoting security, dependable civil service, and countermeasures to radioactivity tailored to ensuring safe industrial development.

(5) Reviving of other parts of the district (included offshore islands) that suffered serious damage due to the earthquake and tsunami.

In all areas, rehabilitation support will include repair or reconstruction where necessary including revitalization of basic services, reconstruction and repair of damaged island roadways, medical facilities, administrative services, and industry. To strengthen the nation, it will be necessary for central government agencies to join with prefectural, city, town, and village governments in the affected areas to promote plans of this nature, and provide the human material support required. It will also be necessary to promote cooperation at the citizen and neighborhood association level, as well as within companies and enterprises. 
Because of the massive expenses related to reconstruction, financing the recovery is expected to remain an ongoing problem. It will also be important to ensure flexibility and promote good ideas within the framework of the existing systems, set and enforce goals based on clear appraisals of the damages, and conduct period evaluations to ensure proper progress is being made.

\section{Considerations}

About the time when restoration, the revival from East Japan great earthquake disaster is completed according to the Asahi Newspaper dated March 1, 2013 [11], it was announced in the questionnaire result that the half of the chief of 42 cities, towns and villages in three prefectures where we will be suffered over 610 years later. The $6.8\left(\mathrm{M}_{\mathrm{w}}\right)$ Great Hanshin Earthquake, also known as the Kobe Earthquake, occurred on January 17, 1995, in the southern part of Hyogo Prefecture [12]. The focus of the earthquake was located $16 \mathrm{~km}$ beneath its epicenter, on the northern end of Awaji Island, approximately $20 \mathrm{~km}$ away from the city of Kobe. Approximately 6,434 people lost their lives (final estimate as of December 22, 2005), of which approximately 4,600 were Kobe residents. Among the major cities affected, Kobe, with its population of 1.5 million, was the closest to the epicenter and was hit by the strongest tremors. At that time, it was Japan's second worst earthquake (after the Great Kanto Earthquake of 1923, which claimed 140,000 lives [13]). The Kobe Earthquake caused approximately 10 trillion (US $\$ 100$ billion) in damage, which amounted to approximately $2.5 \%$ of Japan's GDP at the time. Nevertheless, the city of Kobe recovered due to energetic government office and civic activities, and the main economic indicators for the entire region, such as population, manufacturing sector production, tourism, and consumer spending, have all returned to levels that approximate those before the event. However, it should be noted that damage to Kobe City resulted from the earthquake alone, while Shiogama City and other areas affected by the Great East Japan Earthquake also suffered tsunami damage, along with the issue of radioactive fallout from the Fukushima Nuclear Power Plant accidents. Accordingly, the disaster restoration methods and time required for revival in the latter case can be expected to be different. It is necessary to reflect on the historical experiences and lessons learned from Great East Japan Earthquake and Great Hanshin Earthquake disasters in order to contribute to mitigating future damage from domestic and international disasters. It should also be noted that, even though the Great Kanto Earthquake of 1923 [12] and the Great Hanshin Earthquake of 1975 [13] were huge disasters, the Great East Japan Earthquake was significantly different because it paralyzed and depopulated numerous local governments simultaneously. In addition, it marked the first time the Japanese Government faced challenges related to reviving disaster stricken areas in an era experiencing an ongoing population decline. It is also noteworthy that all of these factors were somewhat overshadowed by the nuclear plant accidents. Thus, the degree of difficulty faced by persons and organizations involved in recovery efforts is unprecedented, and ideas that are fundamentally different from those used in past recovery efforts will be required. 
It is necessary to consider the implementation of those steps in terms of: prevention, mitigation, evacuation, relocation and sheltering.

\section{Conclusions}

At present, approximately 360,000 people continue to reside in evacuation shelters set up in the aftermath of the Great East Japan Earthquake. Meanwhile, the population outflow from the stricken area continues, and while public construction efforts are robust and ongoing, numerous people are unable to find hope there. The stricken area has been hit by tsunami many times in the past, and towns in the area that subsist primarily on marine product industries have recovered each time. Despite this, according to the recent public opinion poll, approximately $50 \%$ of those residing in the area hope "to move to other locations" in the future. Additionally, since it has been decided that new housing will be constructed on the hilly lands above tsunami danger areas, those who intend to remain in the area can expect to wait another two to three years for house construction, and thus must continue to reside in temporary housing until then. Population levels have decreased in other affected cities, towns and villages along the Sanriku Coast, with most of the departures consisting of persons less than 30 years of age. Aggravating the problem in the depopulated region has been the percentage-wise increase in aged persons, and a shortfall of persons able to provide support for victims. Another shortfall has been in the availability of construction materials necessary for recovery efforts, primarily because of the massive amount of public works underway. The hard power required for the construction of roads, houses, railways, etc. is plentiful, but the soft power required for negotiation of lands or houses is drastically short. It may be difficult that the past life will be revived, but the reconstruction will be premature by the wisdom and the effort of people.

\section{References}

[1] Wikipedia, the free encyclopedia, 2011 Tohoku earthquake and tsunami, http://en.wikipedia.org/wiki/2011-T\%c5\%8dhoku-earthquake-and-tsunami $(2013 / 02 / 24)$

[2] Wikipedia, the free encyclopedia, Reconstruction Agency, http://en.wikipedia.org/wiki/Reconstruction-Agency (2013/02/28)

[3] Wikipedia, the free encyclopedia, Japan, http://en.wikipedia.org/wiki/Japan $(2011 / 02 / 24)$

[4] A. Martin, Japan Convulses, Grieves, Moves On, The Japan Times Special Report (2011/03/11)

[5] Shiogama City, About Shiogama, http://www.city.shiogama.miyagti.jp /shiogama/index.html. (2013/02/26)

[6] Images of Matsushima bay Map, bing.com/image

[7] Shiogama City, Reconstruction plan of the Shiogama City caused by the Great East Japan Earthquake Disaster, Shiogama City, 2012 
[8] Ministry of Land, Infrastructure and Transport, Outline of reconstruction pattern in Shiogama City corresponding to the Great East Japan Earthquake Disaster, http://www.mlit.go.jp/common/000209550.pdf. (2013/03/09) (In Japanese)

[9] H. Etoh, Appearance of disaster municipality in the Great East Japan earthquake by statistics and map, Japan Statistical Association, 2013

[10] Wikipedia, the free encyclopedia, Reconstruction Agency, http://en.wikipedia.org/wiki/Reconstruction-Agency (2013/02/28)

[11] Asahi Newspaper, Dappled effect of reconstruction plans, (2013/3/1)

[12] Wikipedia, the free encyclopedia, Great Hanshin Earthquake, http://en.wikipedia.org/wiki/Great-Hanshin-earthquake (2013/03/09)

[13] Wikipedia, the free encyclopedia, 1923 Great Kanto Earthquake, http://en.wikipedia.org/wiki/1923-Great-Kanto-earthquake (2013/03/09) 